\title{
O DESABROCHAR DAS FLORES: OPINIÕES DE ADOLESCENTES GRÁVIDAS SOBRE PLANEJAMENTO FAMILIAR*
}

Lívia de Azevedo Dantas', Luciana Dantas Farias de Andrade², Gigliola Marcos Bernardo de Limaª Alynne Mendonça Saraiva ${ }^{4}$

\begin{abstract}
RESUMO: Pesquisa exploratória descritiva de abordagem qualitativa foi desenvolvida entre março e abril de 2012 com 7 adolescentes grávidas em acompanhamento por Equipe de Saúde da Família com o objetivo de conhecer sua percepção sobre o planejamento familiar. Utilizou-se a entrevista semiestruturada para coleta de dados, da análise de conteúdo surgiram duas categorias: cuidando do jardim - conhecendo os métodos contraceptivos e o desabrochar das flores - a gravidez na adolescência. Os resultados indicaram que ainda existem fragilidades quanto ao conhecimento e uso dos métodos contraceptivos. Além disso, as adolescentes evidenciaram desconhecimento sobre planejamento familiar, porém, em sua maioria, afirmaram que a gravidez ocorreu de forma desejada, desmistificando o fato de que uma gestação na adolescência ocorre de forma inesperada. DESCRITORES: Gravidez na adolescência; Planejamento familiar; Anticoncepção.

\section{THE BLOOMING OF THE FLOWERS: PREGNANT ADOLESCENTS' OPINIONS ON FAMILY PLANNING}

\begin{abstract}
Exploratory and descriptive research with a qualitative approach, undertaken between March and April 2012 with 7 pregnant adolescents being monitored by the Family Health team, with the objective of investigating their perceptions on family planning. Semi-structured interviews were used for data collection, and from the content analysis two categories emerged: Caring for the garden - knowing the contraceptive methods and the blooming of the flowers - pregnancy in adolescence. The results indicated that there are still weak points regarding the knowledge and use of methods of contraception. In addition to this, the adolescents evidenced ignorance of family planning, although most asserted that the pregnancy was planned, demystifying the notion that a pregnancy in adolescence occurs unexpectedly. DESCRIPTORS: Pregnancy in adolescence; Family Planning; Contraception.

\section{EL ABRIR DE LAS FLORES: OPINIONES DE ADOLESCENTES EMBARAZADAS SOBRE PLANEAMIENTO FAMILIAR}

RESUMEN: Investigación exploratoria descriptiva de abordaje cualitativo que fue desarrollada entre marzo y abril de 2012 con 7 adolescentes embarazadas acompañadas por el Equipo de Salud de la Familia con el objetivo de conocer su percepción acerca del planeamiento familiar. Fue utilizada la entrevista semiestructurada para obtener los datos. Del análisis de contenido resultaron dos categorías: Cuidando del jardín - conociendo los métodos anticonceptivos y El abrir de las flores - el embarazo en la adolescencia. Los resultados apuntan que todavía hay fragilidades acerca del conocimiento y uso de los métodos anticonceptivos. Además, las adolescentes evidenciaron desconocimiento sobre planeamiento familiar, sin embargo la mayor parte de ellas afirmaron que el embarazo ocurrió por su voluntad, desmitificando el hecho de que una gestación en la adolescencia ocurre de forma inesperada. DESCRIPTORES: Embarazo en la adolescencia; Planeamiento familiar; Anticoncepción.

\footnotetext{
*Artigo redigido a partir de trabalho de conclusão de curso apresentado à Coordenação do Curso de Graduação em Enfermagem, da Universidade Federal de Campina Grande, em 2012.

${ }^{1}$ Enfermeira. Residente em Enfermagem Materno-Infantil pela Universidade Federal do Rio Grande do Norte.

${ }^{2}$ Enfermeira. Doutora em Enfermagem. Professora do Curso de Graduação em Enfermagem da UFCG.

${ }^{3}$ Enfermeira. Mestre em Enfermagem de Saúde Pública. Doutoranda em Saúde Pública pelo Doutorado Interinstitucional UFCG/ UFPB/FIOCRUZ. Professora do Curso de Graduação em Enfermagem da UFCG.

${ }^{4}$ Enfermeira. Mestre em Enfermagem. Doutoranda pelo Programa de Pós-Graduação em Enfermagem da Universidade Federal da Paraíba - UFPB. Professora do Curso de Graduação em Enfermagem da UFCG.
} 


\section{INTRODUÇÃO}

A adolescência é considerada uma fase de transição da vida infantil para a idade adulta, por isso é marcada por grandes transformações biológicas, emocionais, psicológicas e sociais. É nessa fase da vida que os jovens começam a planejar seu futuro profissional e pessoal; em virtude disso, é um período marcado por grandes conflitos internos ${ }^{(1)}$.

A gravidez na adolescência geralmente é vista como um problema, tanto no âmbito da saúde, como na esfera social. Por ser uma vivência que traz alterações orgânicas e psíquicas intensas, a gravidez, quando acontece no período da adolescência, pode comprometer a saúde física e mental das jovens, além de poder acarretar prejuízos à saúde do bebê.

Os fatores que, mais comumente, são usados para instituir a gravidez na adolescência como um problema de saúde pública estão relacionados a efeitos adversos na saúde da criança ou materna. São exemplos a morte materna, abortos, índices elevados de prematuridade, mortalidade neonatal e baixo peso de recém-nascidos, além da contribuição à perpetuação da pobreza. Pior qualificação profissional, resultado de provável evasão escolar, e a disposição a grande quantidade de filhos, suscitariam em um ciclo de manutenção da pobreza ${ }^{(2)}$.

O Ministério da Saúde, tomando por base o dispositivo da lei do planejamento familiar (Lei n. 9.263/96) determina, como competência do enfermeiro, assistir em concepção e contracepção, empenhando-se em informar os indivíduos sobre as opções para as duas finalidades. Destaca-se a oferta dos métodos anticoncepcionais autorizados e disponíveis no Brasil - Billings, tabela, temperatura, sintotérmico, camisinha masculina e feminina, diafragma, espermicida, dispositivo intra-uterino (DIU), hormonais orais e injetáveis, laqueadura e vasectomia ${ }^{(3)}$.

Através do exposto, percebe-se que falar e promover uma discussão sobre os métodos contraceptivos com os adolescentes se torna primordial para promoção da saúde, prevenção de doenças e resolutividade no planejamento familiar. Mesmo com a divulgação que existe nos dias de hoje, principalmente por meio da mídia, é necessário que os profissionais de saúde sejam capacitados e que recebam condições de trabalho adequadas para realizar o atendimento ao adolescente em todos os níveis de saúde, mas, principalmente em Unidades de Saúde da Família, que é a principal porta de entrada para os demais serviços de saúde.
A importância de desenvolver esta pesquisa está no fato do elevado índice de gravidez na adolescência no Brasil, mesmo tendo ocorrido importante redução na última década. Entre 2000 e 2009, a queda foi de 34,6\% mas os números ainda são preocupantes. Em 2009 no Brasil ocorreram 444.056 partos de adolescentes, só na região Nordeste foram 159.036, dentre esses 10.545 partos foram no Estado da Paraíba. A gravidez na adolescência está presente, principalmente, em famílias de baixa renda ${ }^{(4)}$. Neste contexto, esta pesquisa teve por objetivo analisar o conhecimento das adolescentes grávidas acerca do planejamento reprodutivo.

\section{MÉTODO}

Trata-se de pesquisa descritiva com abordagem qualitativa, realizada em uma Unidade de Saúde da Família (USF), situada na cidade de Campina Grande, Paraíba. Esta unidade foi criada em 1994, sendo uma das equipes pioneiras na cidade, atualmente tem 1.200 famílias cadastradas.

Participaram da pesquisa 7 adolescentes grávidas cadastradas na USF. Foi levado em consideração o período da adolescência de 12 a 18 anos estabelecido no Estatuto da Criança e do Adolescente (ECA) no $\operatorname{art.} 2^{\mathbf{o}(5)}$. Para isso, foram critérios de inclusão: Usuárias da USF pesquisada, adolescentes que estivessem realizando consultas de pré-natal e com autorização dos pais para a realização das entrevistas.

A pesquisa foi submetida ao Comitê de Ética e Pesquisa das Faculdades de Enfermagem e de Medicina Nova Esperança e iniciada após autorização sob protocolo n. 196/11 e CAAE: 0196.0.351.000-11 conforme exigências estabelecidas pela Resolução 196/96 do Conselho Nacional de Saúde.

A coleta de material foi realizada de março a abril de 2012 por meio de entrevista semiestruturada, gravada e transcrita. A identidade das participantes do estudo foi preservada através da criação de pseudônimos com nome de flores. Para a análise do material empírico utilizou-se a técnica de análise de conteúdo juntamente com a literatura pertinente sobre a temática.

\section{RESULTADOS}

As entrevistas foram realizadas com 7 adolescentes com idade entre 15 a 17 anos. Destas, 86\% (6) desistiram de estudar ainda no ensino fundamental. No que se refere ao estado civil, nenhuma adolescente era casada, mas a maioria vivia em união estável. Em 
se tratando de moradia, 57\%(4) das adolescentes moram apenas com seus companheiros. Já, 43\%(3) delas viviam na mesma casa com a família do seu parceiro. Quando questionadas sobre a renda familiar, 71\%(5) responderam um salário mínimo, enquanto que 29\%(2) disseram ter renda de pouco mais de 1 salário mínimo.

Com relação à paridade, 71\%(5) afirmaram estar em sua primeira gestação. Enquanto, 29\%(2) relataram estar em sua segunda gestação, destas uma sofrera aborto na $12^{\mathrm{a}}$ semana de gestação. A respeito de quantas consultas de pré-natal as adolescentes haviam feito durante a gestação, 57\%(4) afirmaram terem feito apenas uma consulta, pois estavam no início da gravidez. Com relação às outras gestantes, $14 \%$ (1) afirmaram ter realizado três consultas até o momento da entrevista; 14\%(1) fizeram 4 consultas; e, 14\%(1) realizaram 7 consultas de pré-natal.

A análise do material empírico constituiu em categorizar e analisar os discursos através da interpretação, onde as entrevistas foram realizadas com base no conhecimento que as adolescentes tinham sobre o planejamento reprodutivo. Desta forma foram emergiram categorias a: Cuidando do jardim: conhecendo os métodos contraceptivos, que teve como sub-categoria O cravo e a Rosa: de quem é a responsabilidade pelo uso do método contraceptivo?, e a segunda categoria $O$ Desabrochar das Flores: a gravidez na Adolescência, que teve como subcategoria Entre rosas e espinhos: os sentimentos que brotam na alma.

\section{Cuidando do jardim: conhecendo os métodos con- traceptivos}

Quando as adolescentes foram questionadas a respeito dos métodos contraceptivos que conheciam, os mais citados foram o anticoncepcional oral e a camisinha, embora tenham sido citados também o DIU, o anticoncepcional injetável e a tabela, como mostram os relatos:

Conheço o anticoncepcional, camisinha, e DIU, ahh,é isso aí. (Papoula)

Tomava comprimido, mas conheço a camisinha, injeção e tabela. (Violeta)

Foi percebido também que elas dão denominações errôneas para identificar os métodos, como chamar o anticoncepcional oral de "remédio" e o injetável de "vacina", como demonstra o relato a seguir:
Conheço só a camisinha, e remédio, injeção, só isso mesmo. (Rosa)

Ao serem perguntadas se já haviam usado algum tipo de método contraceptivo , $86 \%$ (6) usaram anticoncepcional oral para evitar a gestação. E, apenas 14\%(1) usaram o anticoncepcional injetável mensal. O preservativo também foi citado junto à pílula, como mostram os relatos:

\section{Usei o comprimido anticoncepcional. (Dália)}

Só usei remédio e preservativo. (Girassol)

Só injeção. (Rosa)

Em se tratando do lugar onde as adolescentes conseguiam os métodos contraceptivos para uso pessoal a totalidade citou a USF:

Eu fui no posto prá ela me explicar melhor, prá contar, dizer como eu tomava, me explicar melhor. Ai, fui passar primeiro pela médica. (Girassol)

Ao questionarmos as gestantes qual a importância que atribuem ao uso dos métodos contraceptivos, a grande maioria citou o fato de evitar filhos como o principal motivo de prevenção. Já a prevenção de infecções sexualmente transmissíveis foi pouco citada ou esquecida:

Usei prá não engravidar e prá não pegar outras doenças. (Violeta)

Quem quiser usar usa, o que quiser evitar, né? Só não usa quem não quer. Mas, é bom prá não se encher de filho. (Girassol)

A respeito das dificuldades ou dúvidas no uso de método contraceptivo, apenas $14 \%(1)$ relataram mau estar:

Foi por que eu tava tomando comprimido. Ai eu tomava comprimido e me sentia mal, ai falei com a médica e comecei a tomar injeção. (Rosa)

As outras participantes afirmaram não ter dificuldade ou dúvida com uso de algum método, embora a maioria, ao ser questionada sobre o esquema de uso do contraceptivo oral, demonstrou desconhecimento:

Eu tomava 2 dias depois que a menstruação ia embora. (Jasmim) 
Quando eu vim tomar, eu já tava grávida! (Lírio)

No que se refere ao conhecimento que elas tinham sobre Planejamento Reprodutivo, todas fizeram expressão de dúvida ao serem questionadas e afirmaram nunca terem ouvido falar sobre a mesma:

Não sei o que é isso não. (Lírio)

$O$ cravo e a rosa: de quem é a responsabilidade pelo uso do método contraceptivo?

Percebemos no relato de Dália, o quanto ainda é forte as questões relativas ao gênero, no que concerne a responsabilidade pela não concepção, o que ela mesma argumenta que seja pela questão da não fidelidade do parceiro:

Da mulher né? Porque a mulher sempre tem só um parceiro; e o homem a gente nunca sabe, né? (Dália)

No relato de Girassol, observamos que o panorama de liberdade sexual feminina já está presente em seu discurso:

Eu acho que é dos dois, mas na hora de evitar a mulher tem que ter mais cuidado, né? Porque é a mulher que se a gente não se prevenir, né? Eles não tão nem aí. E no caso a gente não sabe, por que hoje a gente tá com ele e pode ser que amanhã já esteja com outro namorado e tal, ai se encher de filho [...] é melhor a mulher mesmo, pra não tá se enchendo de filho de um e de outro! (Girassol)

Lírio também revela que a responsabilidade maior é do homem:

Eu acho queédos dois. Mas, eu acho queémais deles. Sei lá [...] eu acho que mais eles. Por que é obrigação deles usar, quando não usa, é falta de responsabilidade! Eu acho que é mais necessário ele usar do que eu. (Lírio)

\section{O desabrochar das flores: a gravidez na adolescência}

Quando perguntamos as adolescentes grávidas quais os fatores que influenciam/facilitam a ocorrência da gravidez na adolescência, as respostas foram bastante diversificadas, sendo a maioria, de acordo com o posicionamento de quererem a gestação:

Sei lá, acho que é quando a pessoa quer mesmo. Quan- do a pessoa quer. (Dália)

Bom, uma parte eu acho descuido e outra parte eu acho o, o como é que vocêfalou agora? Desejo né? É vontade, é vontade, os dois. (Papoula)

Muitas vezes a maternidade também se dá para satisfazer o desejo do outro, do parceiro, como fala Rosa:

Nada. acho que o primeiro [filho] que eu peguei era por causa que eu gostava muito de criança [...] e esse aqui eu peguei porque ele nunca teve filho ai ele era doido pra ter um ai pronto. (Rosa)

O relato de Lírio mostra que, muitas vezes, os próprios adolescentes sabem da repercussão da gravidez nesta idade como um evento não favorável à própria juventude:

Prá mim, uma adolescente engravidar na minha idade, é falta de responsabilidade. Prá mim o motivo é esse. Só que no meu caso, eu não me arrependo não. (Lírio)

Ao questionarmos as adolescentes se elas tinham amigas que haviam engravidado na adolescência, e se esse fenômeno era comum no bairro, a maioria respondeu que sim:

Sim, aqui no bairro é comum, tem várias. Já vi até meninas engravidarem com 11 anos. (Violeta)

É. Eu tenho uma amiga que engravidou com 13 anos. (Jasmim)

Durante as entrevistas, e analisando os discursos das adolescentes grávidas, percebemos a exacerbação de vários sentimentos que afloraram diante dessa fase tão peculiar; com isso, percebemos que esses mereciam ser relatados.

\section{Entre rosas e espinhos: os sentimentos que brotam na alma}

Os sentimentos das adolescentes acerca da descoberta da gravidez são diversos, o que mostra a complexidade desse fenômeno e a singularidade do que isso representa na vida de cada uma, como mostra o relato abaixo:

Eu pensava em estudar, eu pensava os dois. Uma hora vinha na cabeça, eu quero estudar não quero filho ago- 
ra, e eu só queria, eu dizia né, que eu só queria filho com vinte e cinco anos, ai uma hora dava vontade. (Papoula)

Percebe-se também que não há opinião e desejo concreto sobre a maternidade. Os jovens muitas vezes não percebem as consequências que uma gravidez pode trazer, principalmente nesta fase.

Tipo, eu queria tá grávida, tá entendendo? Mas assim, se eu não tivesse, eu ia ficar feliz. Mas se eu não tivesse, eu ia ficar triste. Eu não entendo também [expressão de dúvida]. (Lírio)

Sei lá, por uma parte eu queria e por outra eu não queria, porquê eu sou novinha demais assim. (Jasmim)

No discurso de Girassol, ela fala da maternidade como uma prova de amor do parceiro:

Sim, foi ele [marido] quem me pediu. Não, eu também já queria. Eu já tava esperando ele me pedir [risos]. Era prá ver se ele gostava mesmo de mim. (Girassol)

\section{DISCUSSÃO}

Diante desse estudo, percebemos que existe grande associação entre gravidez na adolescência e evasão escolar; onde a maioria das adolescentes deixou a escola e afirma querer se dedicar a cuidar da família, colocando isto como seu objetivo de vida. Porém, nenhuma das entrevistadas era casadas e a maioria delas sobrevivia com uma renda familiar de um salário mínimo.

A gravidez na adolescência está relacionada com o aumento nas taxas de evasão escolar, o que implicaria em grande probabilidade de persistirem a diferenças econômicas e sociais gerando um ciclo de pobreza. É sabido que níveis educacionais mais elevados estão associados a menores índices de gestação na adolescência ${ }^{(6)}$.

Autores relacionam a condição econômica desfavorável como um fator social que pode influenciar a gravidez na adolescência. E consideram a gravidez, nessa fase da vida, uma grande probabilidade na manutenção ou entrada no ciclo da pobreza ${ }^{(6-7)}$.

Com relação ao pré-natal, autores afirmam que a adesão das mulheres à consulta está ligada com a assistência prestada pelos serviços e profissionais de saúde. Sabe-se que devem ser realizadas, no mínimo, seis consultas de pré-natal para eficácia na redução das taxas de mortalidade perinatal e materna. Entretanto, com as adolescentes outros aspectos podem ser associados ao início do acompanhamento pré-natal, como o reconhecimento/aceitação da gestação, o apoio/ relacionamento com os familiares e a dificuldade do agendamento da primeira consulta no pré-natal ${ }^{(8)}$.

É importante ressaltar que diante das falas percebe-se uma grande fragilidade do serviço de saúde e escolar em não realizarem ações preventivas sobre o uso dos métodos contraceptivos. São exemplo destas ações palestras, oficinas, rodas de conversas, entre outras.

A falta de insumos limita a escolha dos adolescentes, e até mesmo impõe o uso de determinado método. A oferta dos métodos anticoncepcionais deve estar embasada em uma variedade que permita atender o interesse e a necessidade dos usuários. Deve-se observar, ainda, as características individuais de tolerância aos hormonais, da não-adaptação ao uso do preservativo, da necessidade de uso de método seguro em virtude da existência de fatores de risco para uma futura gestação, e/ou da opção pelo método natural ou pelos métodos comportamentais, dentre outros ${ }^{(9)}$.

Os comportamentos sexuais desprotegidos ou realizados de forma equivocada são decorrentes de várias razões. Dentre elas, está a desinformação, quando os jovens parecem desconhecer o seu período fértil ou o uso correto de anticoncepcionais. Ou mesmo a negligência, por não acreditarem no risco de gravidez ou transmissão de doenças desde a primeira relação sexual $^{(10)}$.

O Ministério da Saúde e a Secretaria Municipal de Saúde necessitam disponibilizar recursos para que os profissionais possam fazer as orientações, o seu trabalho com a população. É imprescindível o fornecimento de métodos, materiais e recursos financeiros para melhorar a saúde reprodutiva dos adolescentes, por meio da educação, treinamento e disseminação de informações à população ${ }^{(11)}$.

Ficou claro também nessa pesquisa que ainda existe pouca, ou nenhuma, informação para os usuários das USF acerca do programa de planejamento familiar. Poucos serviços de saúde oferecem assistência em planejamento familiar esclarecedora e de qualidade, principalmente no que se refere aos jovens que muitas vezes não são incluídos. Percebe-se que nem a família nem os sistemas educacionais e de saúde estão preparados para proporcionar informações e/ou orientações suficientes às reais necessidades desta população ${ }^{(9)}$.

Outro fato interessante a ser discutido no planejamento reprodutivo, é que o casal deve ter a mesma responsabilidade em procurar métodos, não só para evitar 
filhos, como também para evitar infecções sexualmente transmissíveis. Os estereótipos de gênero que surgem na adolescência favorecem o homem com o poder do exercício da sexualidade, o qual acaba delegando à mulher o papel e responsabilidade da contracepção, já que os meninos não são preparados para exercerem a co-responsabilidade na maioria das vezes ${ }^{(12)}$.

Diante das falas proferidas pelas adolescentes a maioria afirmou que queria, realmente, engravidar e constituir uma família, apesar de percebermos sentimentos diversos e conflituosos muitas vezes presentes em seu discurso. Alguns autores ${ }^{(7)}$ referem que a maternidade, para uma grande parcela das jovens, é desejada e se configura como um dos únicos projetos possíveis de reconhecimento social. Além de representar, em alguns casos, um modo de conceber a concretização da identidade feminina.

Além disso, a falta de oportunidades de vida e as carências emocionais se encontram associadas à maternidade na adolescência e ao desejo de ter um filho. Com isso, percebe-se que a maternidade na adolescência é compreendida pelos jovens como uma alternativa viável para lidar com uma série de problemas e situações desfavoráveis presentes em seu contexto sócio-afetivo ${ }^{(13)}$.

A maternidade na adolescência pode fazer parte do projeto de vida das adolescentes, nesta transição entre adolescência e fase adulta. Esse fenômeno parece demarcar, no contexto estudado, a entrada da jovem no mundo adulto, de maneira legítima, uma vez que a adolescente passa a ser reconhecida como adulta pela família, professores e colegas de escola ${ }^{(14)}$.

Diante de tudo, entende-se que os profissionais de enfermagem precisam ser mais atuantes no âmbito do planejamento familiar, principalmente no que concerne a realização de ações de educação em saúde, obedecendo ao perfil sociocultural da população assistida. Não podemos seguir e pensar o que a maioria da literatura nos sugere como o certo, e sim buscar conhecer as reais necessidades e anseios dos usuários que cuidamos para que possamos desempenhar um papel mais eficaz e de excelência.

\section{CONSIDERAÇÕES FINAIS}

Os profissionais de enfermagem devem ser mais atuantes no âmbito da implementação das políticas públicas que regem o planejamento familiar, pois se apreende que a razão de engravidar, para a maioria das adolescentes, foi de realmente querer ter um filho e construir uma família, contrariando muitos autores, que relatam ser a gravidez na adolescência um fator "precoce" ou "indesejado".

É necessário escuta atenta com os adolescentes para conhecer se o desejo de ser mãe é proveniente da necessidade de autorrealização como mulher, ou uma espécie de fuga da realidade vivenciada, derivada da desestruturação familiar, de ambientes hostis ou devido à falta de respeito, de perspectiva de vida e de futuro.

Por isso, a ausência ou limitação nas perspectivas de construção de um projeto de vida podem ser fatores determinantes para a ocorrência de gestação na adolescência. Assim, a gestação na adolescência se apresenta como um projeto viável e valorizado, em um contexto em que não existem muitas alternativas possíveis de implementação de outros projetos de vida.

Por fim, para trabalhar com adolescentes na perspectiva de atenção integral é necessário uma visão abrangente das variadas diferenças culturais, econômicas, sociais, étnicas e políticas, para melhor compreensão do fenômeno da gravidez na adolescência e possibilitará uma reconstrução de práticas de cuidados voltadas a esse público tão peculiar.

\section{REFERÊNCIAS}

1. Madureira VS, Weber AI. Conhecimento de adolescentes mulheres sobre contracepção. Cogitare enferm. [Internet] 2011;16(2) [acesso em 15 jul 2012]. Disponível: http://ojs.c3sl.ufpr.br/ojs-2.2.4/index.php/ cogitare/article/viewFile/20234/14217.

2. Gama SGN, Szwarcwald CL, Leal MC, Theme MMF. Gravidez na adolescência como fator de risco para baixo peso ao nascer no Município do Rio de Janeiro, 1996 a 1998. Rev. Saúde Públ. [Internet] 2001;35(1) [acesso em 07 mai 2012]. Disponível: http://dx.doi.org/10.1590/ S0034-89102001000100011.

3. Brasil. Assistência em planejamento familiar: manual técnico. Brasília: Ministério da Saúde; 2002.

4. Ministério da Saúde (BR). Brasil acelera redução de gravidez na adolescência. Portal da Saúde [Internet] 8 de março de 2010. [acesso em 08 set 2011]. Disponível: http:// portal.saude.gov.br/portal/aplicacoes/noticias/default. $\mathrm{cfm} ? \mathrm{pg}=\mathrm{dspDetalheNoticia \& id \_ area}=124 \& \mathrm{CO}_{-}$ NOTICIA $=11137$.

5. Brasil. Lei. 8.069, de 13 de julho de 1990. Dispõe sobre a proteção integral à criança e ao adolescente. Diário Oficial da República Federativa do Brasil, [internet] 16 jul. 1990 [acesso em 15 jul 2012. Disponível: http://www. portal.mec.gov.br/seesp/arquivos/pdf/lei8069_02.pdf 
6. Chalem E, Mitsuhiro SS, Ferri CP, Barros MCM, Guinsburg R, Laranjeira R. Gravidez na adolescência: perfil sócio-demográfico e comportamental de uma população da periferia de São Paulo, Brasil. Cad. Saúde Pública. [Internet] 2007;23(1) [acesso em 15 jul 2012]. Disponível: http://dx.doi.org/10.1590/S0102311X2007000100019.

7. Ximenes Neto FRG, Dias MSA, Rocha J, Cunha ICKO. Gravidez na adolescência: motivos e percepções de adolescentes. Rev. bras. enferm. [Internet] 2007;60(3) [acesso em 12 jul 2012]. Disponível: http://dx.doi. org/10.1590/S0034-71672007000300006.

8. Spindola T, Silva LFF. Perfil epidemiológico de adolescentes atendidas no pré-natal de um Hospital Universitário. Esc. Anna Nery. [Internet] 2009;13(1) [acesso em 07 mai 2012]. Disponível: http://www.scielo. br/pdf/ean/v13n1/v13n1a14.pdf. (não encontrei o DOI)

9. Queiroz INB, Santos MCFC, Machado MFAS, Lopes MSV, Costa CCC. Planejamento familiar na adolescência na percepção de enfermeiras da Estratégia Saúde da Família. Rev. Rene. [Internet] 2010;11(3) [acesso em 08 mai 2012]. Disponível: http://www. revistarene.ufc.br/vol11n3_pdf/a11v11n3.pdf.

10. Romero KT, Medeiros EHGR, Vitalle MSS, Wehba J. O conhecimento das adolescentes sobre questões relacionadas ao sexo. Rev. Assoc. Méd. Bras. [Internet] 2007;53(1) [acesso em 15 jul 2012]. Disponível: http:// dx.doi.org/10.1590/S0104-42302007000100012.

11. Oliveira TC, Carvalho LP, Silva MA. O enfermeiro na atenção à saúde sexual e reprodutiva dos adolescentes. Rev. bras. enferm. [Internet] 2008;61(3) [acesso em 15 jul 2012]. Disponível: http://dx.doi.org/10.1590/S003471672008000300005 .

12. Luz AMH, Berni NIO. Processo da paternidade na adolescência. Rev. Brás. enferm. [Internet] 2010;63(1) [acesso em 09 mai 2012]. Disponível: http://dx.doi. org/10.1590/S0034-71672010000100008.

13. Reis AOA, Oliveira-Monteiro NR. Sexualidade e procriação na ótica de jovens de periferias sócias e urbanas. Rev. bras. crescimento desenvolv. hum. [Internet] 2007;17(2) [acesso em 10 jul 2012]. Disponível: http:// www.revistasusp.sibi.usp.br/pdf/rbcdh/v17n2/07.pdf.

14. Dias ACG, Teixeira MAP. Gravidez na adolescência: um olhar sobre um fenômeno complexo. Revista Paideia. [Internet] 2010;20(45) [acesso em 04 mai 2012]. Disponível: http://dx.doi.org/10.1590/S0103863X2010000100015. 